\title{
Editorial
}

Journal of Innate

Immunity

\section{The Microbiota: A Microbial Ecosystem Built on Mutualism Prevails}

\author{
Christoph Reinhardt ${ }^{\mathrm{a}} \mathrm{b}$ \\ ${ }^{a}$ Center for Thrombosis and Hemostasis (CTH), University Medical Center Mainz, Johannes Gutenberg University of \\ Mainz, Mainz, Germany; ${ }^{\text {b } G e r m a n ~ C e n t e r ~ f o r ~ C a r d i o v a s c u l a r ~ R e s e a r c h ~(D Z H K), ~ P a r t n e r ~ S i t e ~ R h e i n M a i n, ~}$ \\ Mainz, Germany
}

The colonization status of the host profoundly shapes gastrointestinal immunity [1], but also determines intestinal tissue homeostasis and gut morphology $[2,3]$. It has become evident that the microbiota does not only interfere with the architecture and function of its intestinal habitat $[4,5]$. In fact, the various mutualistic interactions that this ecosystem forms with the host also impact energy metabolism, remote organ functions, and a myriad of inflammatory disease processes [6-9]. Therefore, during the past decade, research on microbiota-host interactions has gained tremendous interest, with publication counts that are steadily increasing year after year.

Medical sciences traditionally had a strong focus on host genetics, which led to detailed insights into pathomechanisms. Due to the analytical limitations, they have so far neglected research on the colonization status of the host, which recently turned out to be a key determinant of numerous immune functions. Luckily, this obstacle has been overcome [10]. The rapid advances in sequencing technologies and experimentation with appropriate gnotobiotic model systems have led to a shift away from the traditional paradigm [11, 12], viewing animals as independent entities without taking into consideration the manifold interactions with the microbiota. These new technologies combined with powerful bioinformatics toolsets have moved our interest towards a metaorganis- mal view that includes the mutualistic interdependence of the host with its colonizing microorganisms.

In this Journal of Innate Immunity themed issue, Daniela Esser et al. [13] provide a broad overview on why studying microbiota-host interactions across the animal kingdom and in non-model organisms is an extremely relevant topic. They discuss how the microbiome affects aging and how it contributes to the health status of metaorganisms. Adding another level of complexity, they emphasize how methodological advances have widened our view on this microbial ecosystem, and how important it is to gain insight into the virome status of the host, which influences the microbiota through manifold routes.

And yes, of course cohousing is essential when analyzing fecal microbiome composition with respect to host genetics and drawing conclusions that are mostly based on associations. In this themed issue, Veronica RingelScaia et al. [14] demonstrate that the maternal influence is a decisive factor for microbiome composition, which in many cases outranks the influence of the host genotype. This study highlights the importance of a proper and standardized study design that includes cohousing and breeding of heterozygous parents. Consequently, one may question the value of conclusions that resulted from experiments neither properly designed nor controlled.

\section{KARGER}

E-Mail karger@karger.com www.karger.com/jin
(C) 2019 The Author(s) Published by S. Karger AG, Basel

Karger

Open access

This article is licensed under the Creative Commons AttributionNonCommercial-NoDerivatives 4.0 International License (CC BYNC-ND) (http://www.karger.com/Services/OpenAccessLicense). Usage and distribution for commercial purposes as well as any distribution of modified material requires written permission.
Prof. Christoph Reinhardt

Center for Thrombosis and Hemostasis (CTH)

University Medical Center Mainz, Johannes Gutenberg University of Mainz

Langenbeckstrasse 1, DE-55131 Mainz (Germany)

E-Mail christoph.reinhardt@ unimedizin-mainz.de 
In this themed issue, Fozia Noor et al. [15] review the influence of the gut microbiota on hematopoietic stem cell transplantation, which is just one striking example of how the microbiota may affect disease processes and clinical treatment outcomes. The authors provide information on how innate immune signaling integrates into adaptive immunity, the differentiation of $\mathrm{T}$ cells, and the modulation of antimicrobial peptide (AMP) secretion. They point out why during the treatment of hematological malignancies the microbiota has to be considered as a relevant factor in the development of graft-versus-host disease, resulting from barrier loss and blood stream infections. Furthermore, they discuss the challenges of antibiotic treatment of hematopoietic stem cell transplantation patients and the possibility of preventing harmful side effects by the use of pre- and probiotics or fecal microbiota transplantation. Moreover, Noor et al. [15] describe how microbiome profiling in the future might contribute to personalized medicine approaches in patients undergoing allogenic hematopoietic stem cell transplantation and they estimate the potential of microbiome analyses as a future biomarker.
Also in this themed issue, the clinical study by Melissa Grant et al. [16] sheds light upon the well-established periodontitis risk factor smoking and how it affects AMP levels in the saliva. The authors describe how smoking influences the release of AMPs, conceivably acting as a selective pressure on oral microbial community members. The authors linked AMP abundance in the saliva to the abundance of individual bacterial taxa. This study points to a mutualistic interrelation between the oral microbiota and the salivary AMP profile, which is disturbed in smokers and has potential consequences for the development of periodontitis.

In conclusion, the microbiome research presented in this Journal of Innate Immunity themed issue illustrates the rapid development of the field and how this will promote shifts of paradigms not only in biology, but even more in immunology and clinical medicine. If one extrapolates the continuous growth of microbiome research and its integration into the various medical disciplines during the past decade, it becomes apparent that immunology needs to put emphasis on understanding the various contributions of this environmental factor.

\section{References}

1 Mowat AM, Agace WW. Regional specialization within the intestinal immune system. Nat Rev Immunol. 2014 Oct;14(10):667-85.

2 Hörmann N, Brandão I, Jäckel S, Ens N, Lillich M, Walter U, et al. Gut microbial colonization orchestrates TLR2 expression, signaling and epithelial proliferation in the small intestinal mucosa. PLoS One. 2014 Nov; 9(11):e113080.

3 Reinhardt C, Bergentall M, Greiner TU, Schaffner F, Ostergren-Lundén G, Petersen LC, et al. Tissue factor and PAR1 promote microbiota-induced intestinal vascular remodelling. Nature. 2012 Mar;483(7391):62731.

4 Abrams GD, Bauer H, Sprinz H. Influence of the normal flora on mucosal morphology and cellular renewal in the ileum. A comparison of germ-free and conventional mice. Lab Invest. 1963 Mar;12:355-64.

5 Endres K, Schäfer KH. Influence of commensal microbiota on the enteric nervous system and its role in neurodegenerative diseases. J Innate Immun. 2018;10(3):172-80.
6 Balmer ML, Slack E, de Gottardi A, Lawson MA, Hapfelmeier S, Miele L, et al. The liver may act as a firewall mediating mutualism between the host and its gut commensal microbiota. Sci Transl Med. 2014 May;6(237): $237 \mathrm{ra} 66$.

7 Ley RE. The gene-microbe link. Nature. 2015 Feb;518(7540):S7.

8 Heiss CN, Olofsson LE. Gut microbiota-dependent modulation of energy metabolism. J Innate Immun. 2018;10(3):163-71.

9 Jäckel S, Kiouptsi K, Lillich M, Hendrikx T, Khandagale A, Kollar B, et al. Gut microbiota regulate hepatic von Willebrand factor synthesis and arterial thrombus formation via Toll-like receptor-2. Blood. 2017 Jul;130(4): 542-53.

10 Quinn RA, Adem S, Mills RH, Comstock W, DeRight Goldasich L, Humphrey G, et al. Neutrophilic proteolysis in the cystic fibrosis lung correlates with a pathogenic microbiome. Microbiome. 2019 Feb;7(1):23.

11 Kuczynski J, Lauber CL, Walters WA, Parfrey LW, Clemente JC, Gevers D, et al. Experimental and analytical tools for studying the human microbiome. Nat Rev Genet. 2011 Dec; 13(1):47-58.
12 Arvidsson C, Hallén A, Bäckhed F. Generating and analyzing germ-free mice. Curr Protoc Mouse Biol. 2012 Dec;2(4):307-16.

13 Esser D, Lange J, Marinos G, Sieber M, Best L, Prasse D, et al. Functions of the microbiota for the physiology of animal metaorganisms. J Innate Immun. 2019. DOI: 10.1159/000495115.

14 Ringel-Scaia VM, Qin Y, Thomas CA, Huie $\mathrm{KE}, \mathrm{McDaniel} \mathrm{DK}$, Eden K, et al. Maternal influence and murine housing confound impact of NLRP1 inflammasome on microbiome composition. J Innate Immun. 2019. DOI: 10.1159/000495850.

15 Noor F, Kaysen A, Wilmes P, Schneider JG. The gut microbiota and hematopoietic stem cell transplantation: challenges and potentials. J Innate Immun. 2019. DOI: $10.1159 / 000492943$

16 Grant M, Kilsgård O, Åkerman S, Klinge B, Demmer RT, Malmström J, et al. The human salivary antimicrobial peptide profile according to the oral microbiota in health, periodontitis and smoking. J Innate Immun. 2019. DOI: $10.1159 / 000494146$. 